\title{
Population Genetic Structure and Demographic History of Primula fasciculata in Southwest China
}

\author{
Guangpeng Ren ${ }^{1,2 *}$, Rubén G. Mateo ${ }^{3,4}$, Elena Conti ${ }^{5}$ and Nicolas Salamin ${ }^{2}$ \\ 1 State Key Laboratory of Grassland Agro-Ecosystems, School of Life Science, Lanzhou University, Lanzhou, China, \\ 2 Department of Computational Biology, Biophore, University of Lausanne, Lausanne, Switzerland, ${ }^{3}$ Departamento de \\ Biología (Botánica), Universidad Autónoma de Madrid, Madrid, Spain, ${ }^{4}$ Centro de Investigación en Biodiversidad y Cambio \\ Global (CIBC-UAM), Universidad Autónoma de Madrid, Madrid, Spain, ${ }^{5}$ Department of Systematic and Evolutionary Botany \\ and Botanic Garden, University of Zurich, Zurich, Switzerland
}

\section{OPEN ACCESS}

Edited by:

Marcial Escudero,

Universidad de Sevilla, Spain

Reviewed by:

Mario Fernández-Mazuecos, Real Jardín Botánico (RJB), Spain

Fabrizio Grassi,

University of Bari Aldo Moro, Italy

${ }^{*}$ Correspondence: Guangpeng Ren rengp@/zu.edu.cn

Specialty section: This article was submitted to Plant Systematics and Evolution, a section of the journal Frontiers in Plant Science

Received: 13 April 2020 Accepted: 17 June 2020

Published: 02 July 2020

Citation:

Ren G, Mateo RG, Conti E and Salamin N (2020) Population Genetic

Structure and Demographic History of Primula fasciculata in Southwest China.

Front. Plant Sci. 11:986. doi: 10.3389/fp/s.2020.00986
Understanding the factors that drive the genetic structure of a species and its responses to past climatic changes is an important first step in modern population management. The response to the last glacial maximum (LGM) has been well studied, however, the effect of previous glaciation periods on plant demographic history is still not well studied. Here we investigated the population structure and demographic history of Primula fasciculata that widely occurs in the Hengduan Mountains and Qinghai-Tibetan Plateau. We obtained genomic data for 234 samples of the species using restriction site-associated DNA (RAD) sequencing and combined approximate Bayesian computation (ABC) and species distribution modeling (SDM) to evaluate the effects of multiple glaciation periods by testing several population divergence models and demographic scenarios. The analyses of population structure showed that $P$. fasciculata displays a striking population structure with six groups that could be identified genetically. Our ABC modeling suggested that the current groups diverged from ancestral populations located in the eastern Hengduan Mountains after the largest glaciation occurred in the region ( 0.8-0.5 million years ago), which is consistent with the result of SDMs. Each current group has survived in different glacial refugia during the LGM and experienced expansions and/or bottlenecks since their divergence during or across the following Quaternary glacial cycles. Our study demonstrates the usefulness of population genomics for evaluating the effects of past climatic changes in alpine plant species with shallow population structure.

Keywords: demography, genetic structure, Hengduan Mountains, population genomics, Quaternary climatic changes

\section{INTRODUCTION}

Plant populations are not randomly arranged assemblages of genotypes but are structured in space and time (Loveless and Hamrick, 1984). Because of the limited mobility of plants, their genetic structure implies spatial structure, where genetic differentiation increases with geographic distance (Wright, 1943). Yet, recent empirical studies have put forward that geographic distance by itself fails 
to fully explain the genetic variation observed in natural systems (e.g., Shafer and Wolf, 2013). In fact, geographic, environmental, historical, and intrinsic factors (e.g., mating system) have been suggested to simultaneously act as drivers of spatial genetic patterns at different spatial scales (Wang et al., 2013; MuñozPajares et al., 2017; Ren et al., 2017). Identifying the factors that drive the genetic structure of a plant species is an important first step not only to understand speciation, adaptation, and genetic change (Antonovics, 1968), but also to help in population management. In the latter case, the spatio-temporal dynamics of population histories can profoundly impact their future evolutionary potential (e.g., Lanier et al., 2015). This is especially true for climate-sensitive species inhabiting highly fragmented environments, such as mountain ranges.

One of the key high-altitude biodiversity hotspots in the world where these processes can be studied are Mountains of Southwest China, i.e., the Hengduan Mountains region. They were formed by recent uplifts of mountains during the late Miocene and Pliocene (Li and Fang, 1999; Myers et al., 2000; Zheng et al., 2000; Mulch and Chamberlain, 2006; also reviewed in Favre et al., 2015; Renner, 2016; Muellner-Riehl, 2019). Additionally, the climate in the region and the Qinghai-Tibetan Plateau (QTP) has changed drastically during the Quaternary, and the extent and timing of glaciations remain controversial, especially for the old glaciations (Ou et al., 2015; Muellner-Riehl, 2019). However, recent studies have suggested that four major glaciations have likely occurred since 1.2 million years ago $(\mathrm{Ma})$, which are the Xixiabangma (0.8$1.17 \mathrm{Ma})$, Naynayxungla (0.5-0.72 Ma), Guxiang (0.13-0.3) and the Last Glaciation (0.01-0.07 Ma; Shi, 2002; Zheng et al., 2002; Ou et al., 2015). The Naynayxungla Glaciation is thought to be the largest glaciation that occurred in this region (Shi, 2002; Zheng et al., 2002; Ou et al., 2015). The origin and maintenance of the high biodiversity in this region are the result of its specific topographic features and profound ecological heterogeneity created by the historical orogenesis and associated climatic changes (Wu, 1987). Today, the Hengduan Mountains are characterized by parallel and deep North-South oriented valleys surrounded by high mountain peaks (Figure 1). The mountains display drastic altitudinal variations ranging from $1,000 \mathrm{~m}$ to numerous peaks above $6,000 \mathrm{~m}$, and the area is particularly vulnerable to climate change (Zheng, 1996; Yao et al., 2007). With such a complex geological, climatic, and ecological diversity, the region has attracted attention of numerous biologists to study the factors affecting species diversification and evolution (e.g., Xing and Ree, 2017; reviewed in Qiu et al., 2011; Liu et al., 2014; Wen et al., 2014; Mosbrugger et al., 2018). Some studies focused on species-level diversification that resulted from the uplift of the QTP and Hengduan Mountains (e.g., Liu et al., 2002; Liu et al., 2006; Ren et al., 2015), while others looked at intraspecific divergence to investigate the effects of past geological events and Quaternary climatic fluctuations on population genetic structure (e.g., Wang et al., 2009; Liu et al., 2013). For example, studies on Quercus aquifolioides (Du et al., 2017), on several closely related Picea species (Li et al., 2013)and on Taxus wallichiana (Liu et al., 2013) have suggested that plant species in the Hengduan Mountains tend to show long-term demographic stability and survival in multiple refugia. Although numerous phylogeographic studies on herbs, shrubs, and trees in this region have suggested several phylogeographic patterns (summarized in Muellner-Riehl, 2019), a comprehensive understanding of the factors triggering current genetic structure and a detailed demographic scenario in response to the Quaternary climatic fluctuations in this region are

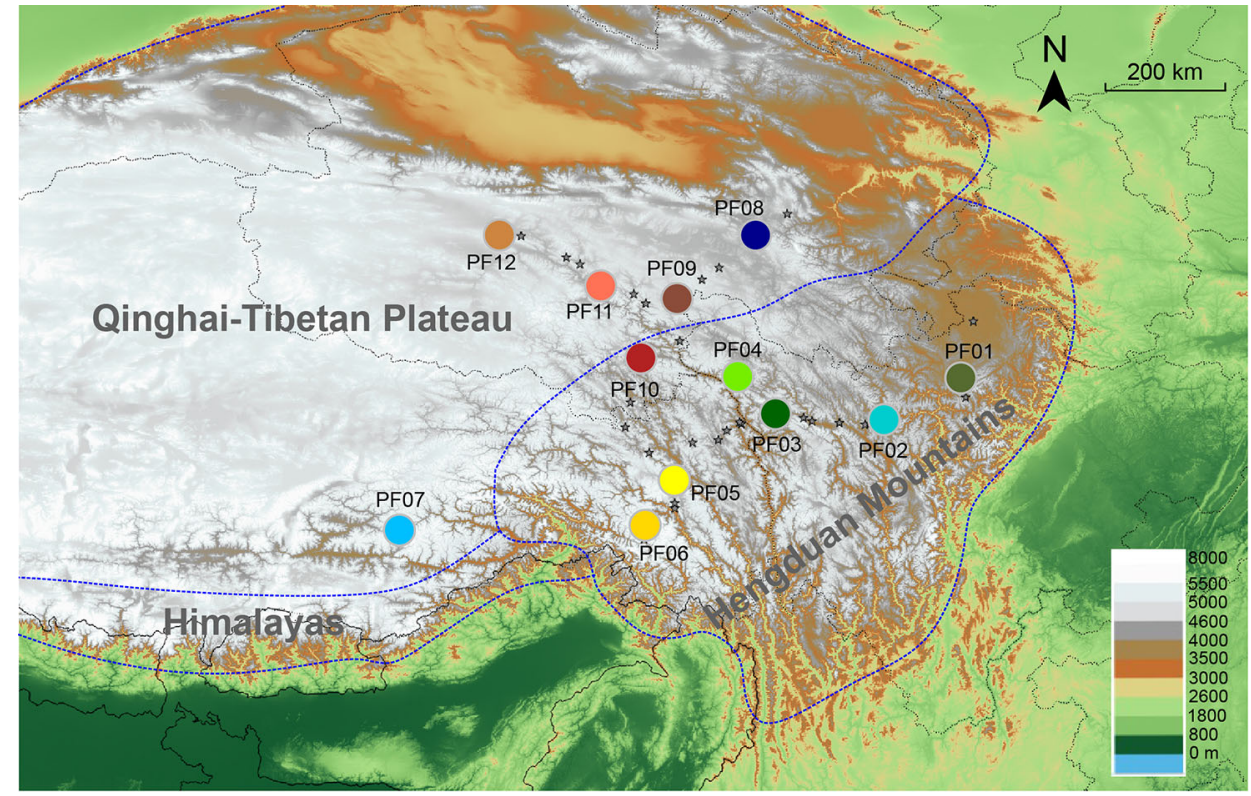

FIGURE 1 | Sampling locations of all 61 populations of $P$. fasciculata (gray stars) and the 12 selected populations (large colored circles) used for genomic analyses in this study. The three regions of the Tibeto-Himalayan region were delineated by blue dotted lines. 
still unclear because of the limited genetic information used in most previous studies.

Integrative approaches combining population genomics (e.g., Ren et al., 2017) with niche modeling (Guisan and Zimmermann, 2000) have helped to understand current spatial genetic patterns and the processes (Theodoridis et al., 2016). Population genomic data can provide accurate estimates of genetic structure (Avise, 2010; Narum et al., 2013) and increased accuracy when estimating demographic parameters (e.g., Emerson et al., 2010; Bourret et al., 2013; Lanier et al., 2015; Ren et al., 2017), whereas species distribution models allow to predict geographic areas that are part of the ecological niche of species at different temporal and spatial scales. A recent study based on these approaches has significantly advanced our understanding of the response of alpine plant species to Quaternary climatic changes in the Himalayas (Ren et al., 2017). Although Next-Generation Sequencing (NGS) methods have recently become cost-effective, the application of population genomics on the taxa distributed in the Hengduan Mountains remains rare because of its remoteness and inaccessibility, and consequently, such genomic level studies are particularly needed for this region to provide a better understanding of evolutionary history of species.

Here we focus on Primula fasciculata (Primulaceae), one of the most widely distributed alpine plant species in the Hengduan Mountains and QTP (Hu and Kelso, 1996; Figure 1). It is an insect-pollinated, heterostylous, herbaceous, perennial plant that occurs in diverse habitats at elevations ranging from 2,900 to 5,000 $\mathrm{m}$. As an outcrossing small herb of variable height $(2-10 \mathrm{~cm}), P$. fasciculata disperses its seeds largely by gravity and usually grows in wet meadows or along hill-streams (Hu and Kelso, 1996; Richards, 2003). A recent study, focused on $P$. fasciculata and its two closely related species (i.e., $P$. tibetica and $P$. nutans) at species level and investigated interspecific divergence and the factors that affected the maintenance of species boundaries, has indicated that P. fasciculata diverged from $P$. tibetica during the Pliocene and experienced expansion during the Quaternary (Ren et al., 2018). However, the population structure and demographic history of $P$. fasciculata and the factors affecting its demography were not involved in Ren et al. (2018). Here, we use an integrative approach combining genomic phylogeography with niche modeling to test several demographic scenarios corresponding to specific hypotheses related to the effects of Quaternary climatic fluctuations on alpine species in this region. The aims of our study are to: i) identify the population structure of $P$. fasciculata and understand the factors driving it; and ii) compare several detailed demographic scenarios for $P$. fasciculata using ABC modeling and test these hypotheses with species distribution models to evaluate the effects of Quaternary climatic changes on the evolution of this species.

\section{MATERIALS AND METHODS}

\section{Data Set}

The data set of $P$. fasciculata (Dryad doi: https://doi.org/10.5061/ dryad.tt8n46q; File 1-D2) used in Ren et al. (2018) that comprises 234 individuals from 12 populations with $17.8 \%$ missing data was re-analyzed in this study to further investigate the population structure and demographic history of this species. In order to obtain estimates of neutral population genetic structure, the detected 106 outlier SNPs by both BAYESCAN and LOSITAN in this species (Ren et al., 2018) were removed for the downstream analyses. Therefore, all results in this study were derived from the neutral data set containing 5,980 single-SNP loci. This neutral data set in Ren et al. (2018) was used only to test whether population divergence of the neutral genomic fractions was driven by geographical or environmental or both factors. The result showed that both factors played a role, which was the only result derived from this data set in our previous paper. In this study, on the basis of this data set, we did multiple population structure analyses and ABC modeling to investigate population structure and demographic history of this species. Therefore, the hypotheses behind and the analytical methods were completely different between the two studies.

The 12 populations were selected from our 54 sampled populations to be representative of both the geographical distribution and the diversity of ecological niches of this species. We estimated the latter by extracting the 19 bioclimatic variables of WorldClim (http://www.worldclim.org/current) from the occurrences of the individuals sampled in the 54 populations. We did a principal component analysis (PCA) using the prcomp function in the stats package of $\mathrm{R}$ and identified the 12 populations based on the PC1 and PC2 axes (explained nearly $82 \%$ of the variance; Figure S1). Seventeen to 20 individuals were sampled in each population, making sure that all individuals sampled were at least $20 \mathrm{~m}$ apart. The detailed location information of the 12 populations was listed in Supporting Information Table S1.

\section{Characterization of Population Genetic Structure}

Population genetic structure of $P$. fasciculata was estimated by using the Bayesian method implemented in STRUCTURE 2.3.4 (Pritchard et al., 2000) and by principal components analysis (PCA). Structure analyses were performed under the "Admixture model" and the "Correlated allele frequency model" with Kvalues ranging from 1 to 12 . Ten independent runs were performed for each value of $\mathrm{K}$ using $1 \times 10^{5}$ generations for the burnin and $2 \times 10^{5}$ generations for the sampling. The optimal $\mathrm{K}$ was chosen using the delta-K method of Evanno et al. (2005) as implemented in STRUCTURE HARVESTER (Earl and VonHoldt, 2012). The coefficient for cluster membership of each individual was averaged across the ten independent runs using CLUMPP (Jakobsson and Rosenberg, 2007) and plotted using DISTRUCT (Rosenberg, 2004). PCA was performed with the glPCA function in adegenet package (Jombart, 2008) in $\mathrm{R}$ to identify the major axes of variation of the populations.

Pairwise $F_{\mathrm{ST}}$ values and analysis of molecular variance (AMOVA) among populations were calculated in GENODIVE v.2.0b27 (Meirmans and Van Tienderen, 2004), and significance was determined using $1 \times 10^{4}$ permutations. AMOVA for 
populations that were further clustered into several groups based on the STRUCTURE and PCA results (Table S2) was applied to evaluate which grouping strategy explains the highest percentage of total variance among groups, which was used to select the most likely strategy of the grouping for $\mathrm{ABC}$ modeling.

The first three components of the PCA performed on the genetic data and the geographic coordinates (latitude and longitude) of the 12 populations were used in a Procrustes analysis using the $\mathrm{R}$ package vegan (Oksanen et al., 2013). This analysis minimizes the sum of squared Euclidean distances between two sets of points by rotating one set of points to match the other, while preserving the relative distances among all points within the map (Wang et al., 2012). The similarity of the two maps is quantified using the Procrustes similarity statistic $t_{0}$ (Wang et al., 2010; Wang et al., 2012). We used the protest function in vegan to test the probability of observing a similarity statistic higher than the observed to if no geographic pattern is assumed using $1 \times 10^{5}$ permutations (Wang et al., 2012).

We further used BARRIER v2.2 (Manni et al., 2004) to compute the Monmonier's maximum-difference algorithm for identifying biogeographic boundaries or areas exhibiting the largest genetic discontinuities between population pairs based on pairwise genetic distances $\left(F_{\mathrm{ST}}\right)$. We randomly selected 5,000 loci from the neutral data set 100 times to generate $100 F_{\mathrm{ST}}$ distance matrices by using populations module in the STACTS v1.30 (Catchen et al., 2013). The number of barriers was set to vary from 1 to 10 , reflecting their descending order of relative importance ("priority") for genetic dispersion (Manni et al., 2004). The robustness of the genetic boundaries was assessed by running BARRIER on the $100 F_{\mathrm{ST}}$ distance matrices.

\section{Estimates of Historical Demography}

To decipher the historical demography of $P$. fasciculata, we estimated divergence times, admixture, and changes in population sizes among different groups of population using approximate Bayesian computation (ABC) modeling. We stratified the procedure in three steps (Figure 2): (1) we investigated the most likely tree topologies for the three main lineages (see Results) that were identified by the PCA analyses among 13 scenarios describing all possible topologies (Figure 2; Table S2); (2) we split the three main lineages into six groups based on AMOVA analysis on multiple grouping strategies (see more details in Results), i.e., L3 was split into G3, G1, and G2; L1 was split into G4 and G5; L2 was not split and renamed as G6 (see Results; Figure 2; Table S2). Based on the best-supported tree topology obtained in (1) and the STRUCTURE result, and given the fact that G1 had the highest altitude distribution (Table S1) and was sampled in the westernmost of the distribution of the species (suggesting that G1 was not likely ancestral), we fixed the ancestor of G3 as the most recent common ancestor for all groups, then G6 and G1 originated from G3, and G2 originated from the admixture between G3 and G6. Finally, we set two scenarios to model the divergence order of G4 and G5 from G3. This step was conducted to estimate the divergence times among the six groups; (3) we tested changes in population sizes of each of the six groups in the recent past among four scenarios (Figure 2; Ren et al., 2017): i) old expansion; ii) recent expansion; iii) expansion followed by shrinkage; iv) expansion followed by shrinkage and a new expansion event. Five individuals that had the least missing data from each of the 12 populations were selected for steps 1 and 2 to reduce computational time. For step 3 , we used those same five individuals for the two groups (i.e., G3 and G6) that contained multiple populations, whereas all individuals were used for the four groups (i.e., G1, G2, G4, and G5) that included only one population.

For each step, we tested different scenarios using DIY-ABC v.2.1.0 (Cornuet et al., 2010; Cornuet et al., 2014). We selected for these analyses a single SNP per locus, which had to be present in (i) at least $80 \%$ of the individuals from each lineage/group and (ii) all lineages/groups. We chose a minor allele frequency (MAF) of 0.01 to increase the mean level of genetic variation of both the observed and simulated data sets and to reduce the proportion of loci that may correspond to sequencing errors. The data sets used for the ABC modeling and the distributions of prior probabilities are summarized in Table $\mathbf{S 3}$. We selected all summary statistics to generate a reference table (on average $10^{6}$ data sets per scenario). The parameters defining each scenario (i.e., population sizes, divergence times, and/or times of population size changes) were considered as random variables drawn from prior distributions. For each simulation, DIY-ABC drew a value for each parameter from its prior distribution and performed coalescent simulations to generate a simulated pseudo-observed data set (POD) with the same number of gene copies and loci per lineage/group as those observed. It then calculated summary statistic for each POD and the observed data. Based on a distance and a tolerance, it decided for each POD whether its summary statistic was sufficiently close to that of the observed data. We used $1 \%$ of the simulated data sets closest to the observed data to estimate the relative posterior probabilities for each scenario via logistic regression. Posterior distributions of historical demographic parameters based on the most likely scenario (Cornuet et al., 2010) were estimated. The time parameters are estimated in generations and converted into years by multiplying by the generation time, which was set to one year (Ren et al., 2017). Finally, for each step, we performed an evaluation of the fit of each scenario to the data sets by running a model-checking analysis following Cornuet et al. (2010).

\section{Species Distribution Models}

We generated species distribution models (SDMs; Guisan and Zimmermann, 2000) to evaluate the potential effects of past climatic changes on the distribution of $P$. fasciculata and to compare such effects with the demographic changes modeled by ABC. An ensemble model (Araújo and New, 2007) was generated by the combination of three different statistical techniques: generalized linear model, gradient boosting machine and random forests, as implemented in the $\mathrm{R}$ package biomod2 (Thuiller et al., 2009). A total of 74 occurrences were used as presences data to calibrate the models. The performance of the model was assessed by randomly splitting ten times (crossvalidation) the data into an $80 \%$ data set to generate the models and a $20 \%$ data set to estimate their predictive accuracy (AUC statistic). According to Ren et al. (2017), the paleo-climatic conditions of the last interglacial (LIG) in this area predicted 
Step 1
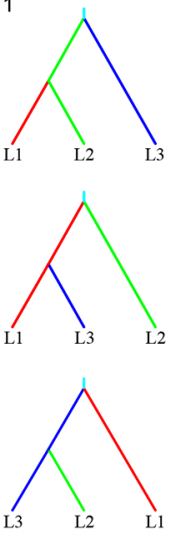
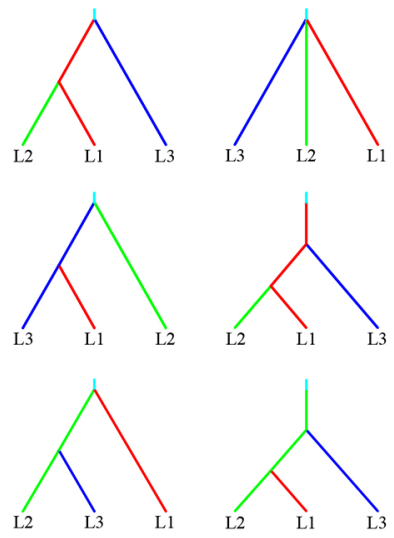
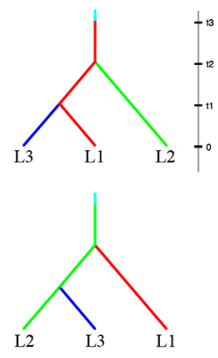

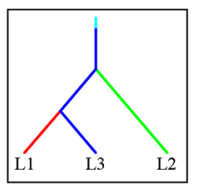

$-N A$
$-N 3$

- N2

Step 2
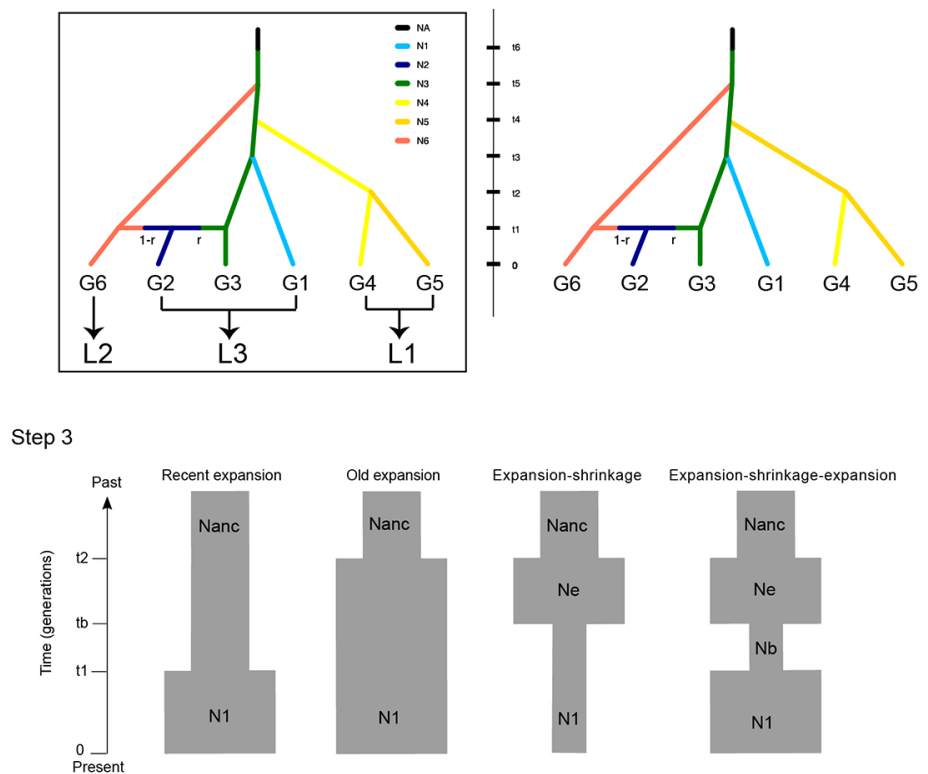

FIGURE 2 | Alternative demographic scenarios for the three steps analyzed by DIY-ABC. The best-fit scenario was indicated by square in steps 1 and 2.

large differences of precipitation compared with the present and the last Maximum Glacial (LGM), resulting in the failure of projection for the LIG, which was also true in the present projection for the LIG (Figure S2). Therefore, in this study, we estimated the potential distributions for the 1) the present; 2 ) the LGM (0.022 Ma), and 3) the Marine isotope stage 19 (MIS19, $\sim 0.787 \mathrm{Ma}$ ). As predictors, we used the bioclimatic variables from PaleoClim (http://www.paleoclim.org/, Fordham et al., 2017; Brown et al., 2018; Karger et al., 2017 REF) at 2.5 arcminutes resolution. In order to avoid multicollinearity, we ran a Pearson correlation analysis by pairs for the 14 bioclimatic variables available for all the periods (for MIS19, monthly maximum and minimum temperatures are not available). In each pair with a correlation value greater than 0.7 (Dormann et al., 2013) we removed one climate variable. The climatic variables finally used to calibrate the SDMs were: temperature seasonality (bio4), mean temperature of coldest quarter (bio11), precipitation of wettest month (bio13), precipitation of driest month (bio14), precipitation seasonality (bio15) and precipitation of coldest quarter (bio19).

\section{RESULTS}

\section{Structuring of Population Genetic Variation}

Although the optimal $K$ value of the STRUCTURE analyses based on the $\Delta K$ method of Evanno was $K=2$, the differences of $\Delta K$ among $K$ values were very small (Figure 3 ). The $\Delta K$ of the second most probable $K$ value $(K=6)$ differed from the optimal one by only 2 . Other $K$ values (3, 4, 5, and 9) also received considerable support. We decided to show all these $K$ values in Figure 3 and combined them with the PCA results to capture the most reasonable set of lineages for the ABC modeling. 

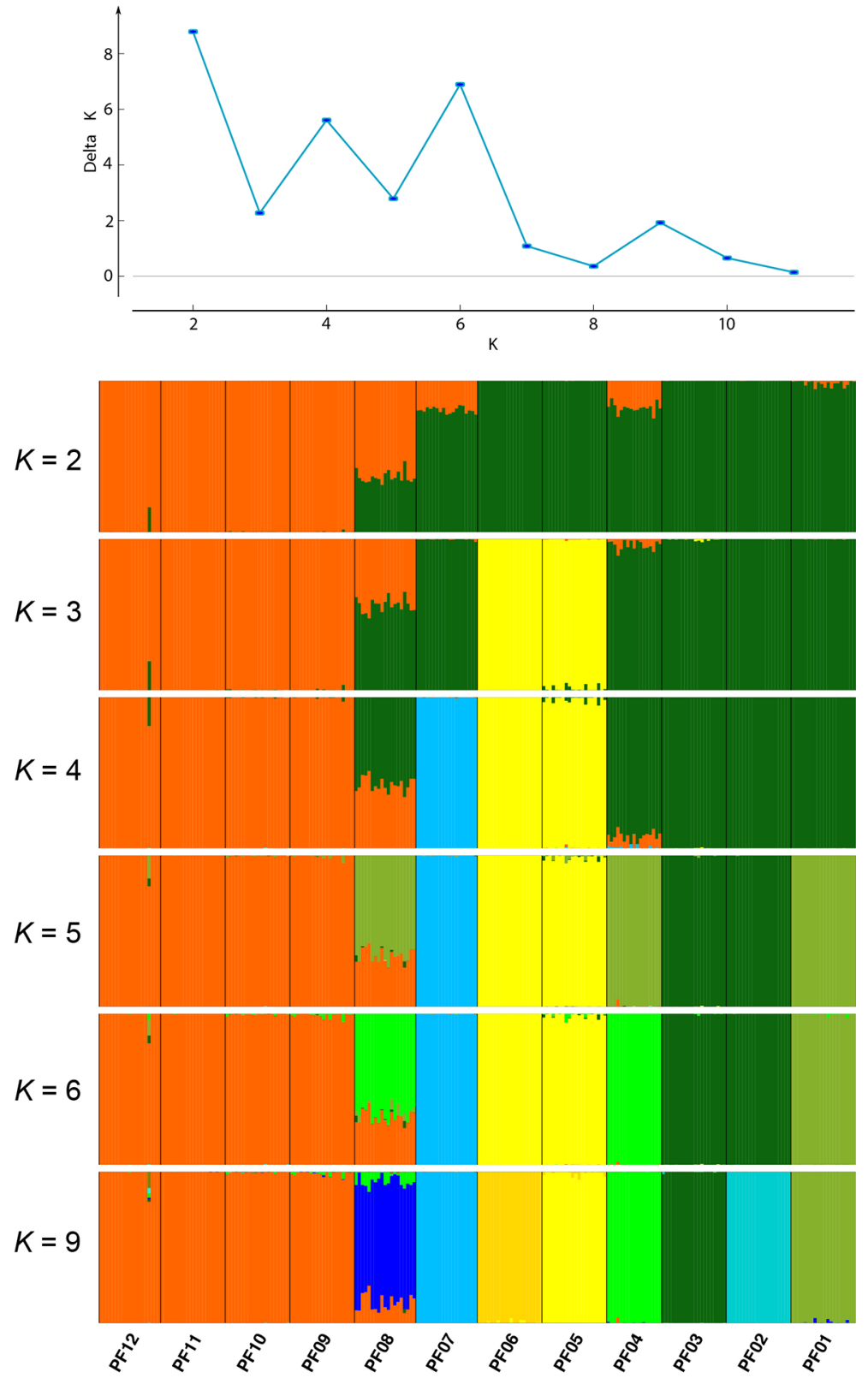

FIGURE 3 | $\triangle$ K values identified using STRUCTURE HARVESTER and plots of posterior probabilities for individuals of $P$. fasciculata assigned to $K$ genetic clusters from STRUCTURE analyses for $K=2-6$ and 9 . Populations are delimited by black lines, with the corresponding population names listed along the bottom of the plot.

The first two PCA axes identified three main genetic lineages and explained $13.04 \%$ and $7.76 \%$ of the total variation, respectively (Figure 4). The two southwestern populations (PF05, PF06) and four northwestern populations (PF09-PF12) formed two separate lineages (L1 and L2), while the rest of the populations form a third lineage (L3; Table S2). The three main lineages (L1-L3) were used in step 1 of the ABC modeling to identify the most likely population tree topology.

In order to investigate the most likely strategy of grouping for the $\mathrm{ABC}$ modeling, we further assigned the 12 populations into four, five, six or seven groups based on the PCA and STRUCTURE analyses (Figures 3 and 4 ). The detailed information of different grouping strategies was summarized in Table S2. The strongest signature of population spatial differentiation was obtained by AMOVA analysis $(22.2 \%$ of total variance; Table S4) when populations were assigned to six groups. We therefore used the six groups in step 2 of the ABC modeling to estimate the divergence times among these groups, and in step 3 to estimate the demographic changes for each of them. The six groups were identified as following: the third axis 

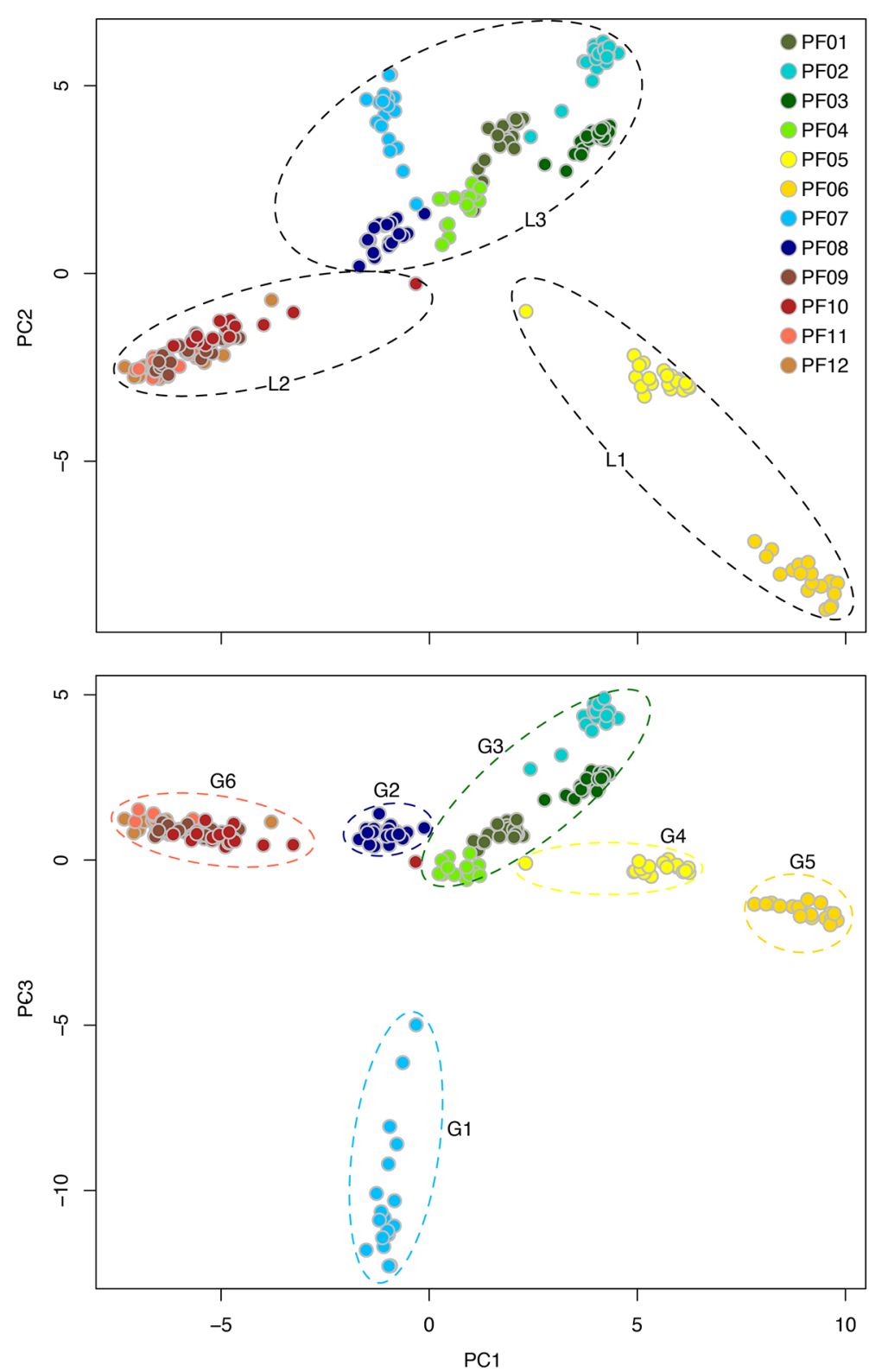

FIGURE 4 | Distribution of individuals of $P$. fasciculata along PC scores (PC1, 13.04\% vs. PC2, 7.76\%; PC1 vs. PC3, 6.12\%) of genetic variation based on the analysis of SNP dataset; individuals are color-coded according to their population identities (see Figure 1). The three lineages and six groups used for ABC modeling are indicated.

of the PCA (PC3; 6.12\% of the total variation) showed a separation of population PF07 from lineage L3, which was also shown when $K=4$ in the STRUCTURE. We identified this population as G1. Looking at $K$ values from $K=2$ to $K=6$, population PF08 was always represented as an admixed population, which was labeled as G2. The remaining populations of L3 were grouped as G3. The two populations (L1) that diverged from each other in the PCA (Figure 4) were identified as G4 and G5. The four northwestern populations form the sixth group (G6; Table S2) evident both in STRUCTURE and PCA.
Procrustes analysis was used to quantify the association between the genetic variation of populations and their geographic locations. The first two PC spaces identified a significant similarity score $\left(t_{0}=0.579, P_{-}\right.$value $\left.<10^{-5}\right)$, which increased to $t_{0}=0.777$ when genetic variation in PC1 and PC3 spaces were considered (Figure 5A). This was caused by the clear separation of the most geographically isolated population PF07 from other populations by the PC3 axis. Individuals from G6 are genetically more similar with each other than would be expected given the geographic distance among the populations forming this group. The general pattern of association with geography for 

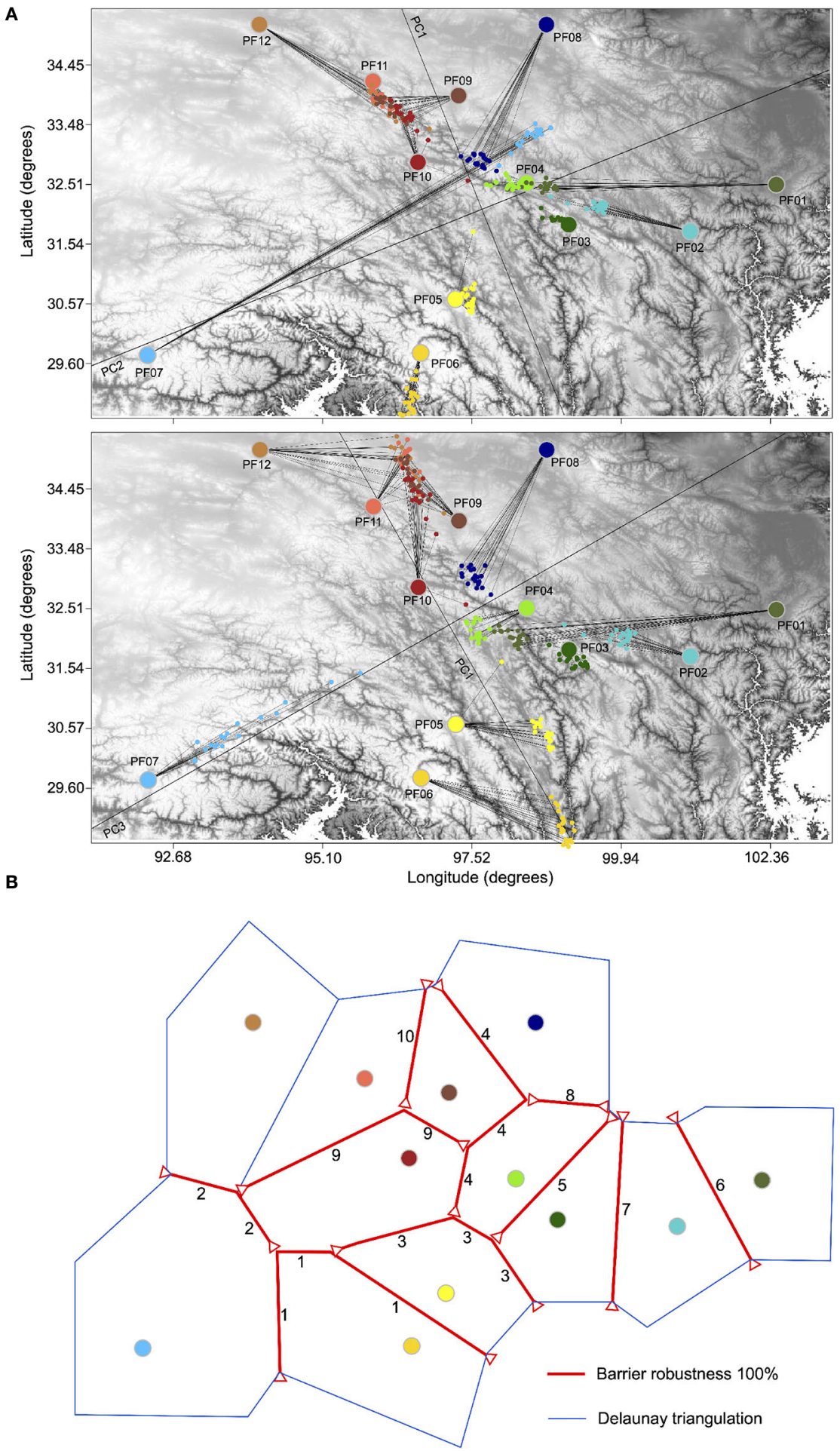

FIGURE 5 | (A) Procrustes-transformed PCA plot of genetic variation with each individual of $P$. fasciculata mapped in PC space (the small circles) relative to the geographic location of populations (the larger circles). Black lines show the orientation of the genetic space relative to the geographic longitude and latitudinal axes. The length of the line connecting individuals in PC space to their geographic location represents the extent of the deviation from the expected pattern of genetic variation based on geography. (B) Result of BARRIER analysis showing the spatial separation of $P$. fasciculata populations. All the ten barriers (red lines) are highly supported over $100 F_{\mathrm{ST}}$ distance matrixes. Barriers are delimited by small red triangle. Numbers (1-10) represent descending order of relative importance ("priority"). 
the rest of populations was robust, indicating high level of population divergence. Such level of divergence was also evident in the BARRIER analysis that gave high support to all ten barriers (bootstrap support 100\%; Figure 5B). The presence of such strong barriers between $P$. fasciculata populations indicates an abrupt change in the genetic profile of populations across the species distribution. Although the ranking of the population barriers (Figure S3) was not in agreement with the STRUCTURE and PCA analyses, the general pattern of spatial genetic structure identified by the BARRIER analysis was consistent with the other analyses. Differentiation among populations was significant, with $F_{\mathrm{ST}}$ values ranging from 0.088 to 0.604 with a mean value of 0.377 (Table S5), which was consistent with AMOVA for the total data set $\left(F_{\mathrm{ST}}=0.306\right.$; Table S4).

\section{Estimates of Historical Demography}

We used a three-step procedure to estimate the demographic history of P. fasciculata. Among the 13 scenarios tested in step 1, the scenario depicting an origin of both L1 and L2 from L3, provided the best fit to our data, with posterior probabilities significantly higher than the other scenarios $(0.995,95 \%$ credible interval (CI) 0.99, 1.00; Table S6; Figures 2 and S4). According to the main tree topology inferred from step 1, the analyses done in step 2 showed that groups G1, G6, and G4/G5 (i.e., alternative scenarios; Figures 2 and S4) originated from G3, while G2 was formed by admixture between G3 and G6. The scenario where G4 originated from G3 and later G5 diverged from G4 fitted the data much better (0.93, CI: 0.93-0.94; Table S6; Figure 2). A check of the goodness-of-fit of the distributions of the parameters for the scenarios with the real data set further indicated that scenarios 13 and 1 were the best-supported scenarios for step 1 and step 2, respectively (Table S7).
Modeling the changes in population size for each group (step 3) recovered complicated demographic histories for the six groups. Analyses for G3 supported a scenario of "expansionshrinkage," while G2, G4 and G6 were better modeled by a scenario of "expansion-shrinkage-expansion." The other two groups (G1 and G5) were better modeled by a scenario of "recent expansion" (Table S6).

We estimated the divergence times and the population sizes as well as the timing and extent of these changes for the six groups. Group G3 was found to be the ancestor of $P$. fasciculata and started to expand its distribution ca. 0.60 Ma (95\% highest posterior density (HPD): 0.27-0.86 Ma; Figures 6 and S3; Table S8), followed by a slight bottleneck around 0.038 Ma (HPD: 0.004-0.075 Ma). G6 diverged from the ancestral populations formed by G3 ca. $0.47 \mathrm{Ma}$ (HPD: 0.38-0.55 Ma; Table S9). It started to expand until ca. 0.36 Ma (HPD: 0.18-0.49 Ma), before experiencing a bottleneck ca. 0.06 Ma (HPD: 0.02-0.09 Ma; Table S8). Then, it quickly expanded just after the LGM. During the first expansion of this group, it came into secondary contact with the ancestral populations of G3, exchanged genes and resulted in the formation of G2 around 0.12 Ma (HPD: 0.07$0.17 \mathrm{Ma}$; Table S9). G2 experienced ancient expansion (0.10 Ma) and shrinkage $(0.054 \mathrm{Ma})$ before and during the last glaciation (i.e., 0.015-0.075 Ma), respectively, and a recent expansion after the LGM. G1 diverged from the ancestral populations ca. 0.36 Ma (HPD: 0.23-0.49 Ma) and stayed stable through time before experiencing a recent expansion after the LGM. G4 diverged from G3 ca. 0.41 Ma (HPD: 0.26-0.54 Ma) and started to expand before experiencing a bottleneck during the last glaciation. A recent expansion after the LGM was also detected for this group. G5 was isolated from the ancient expansion of G4 (0.15 Ma, HPD: $0.09-0.21 \mathrm{Ma}$; Table S9) and experienced a recent expansion after the LGM.

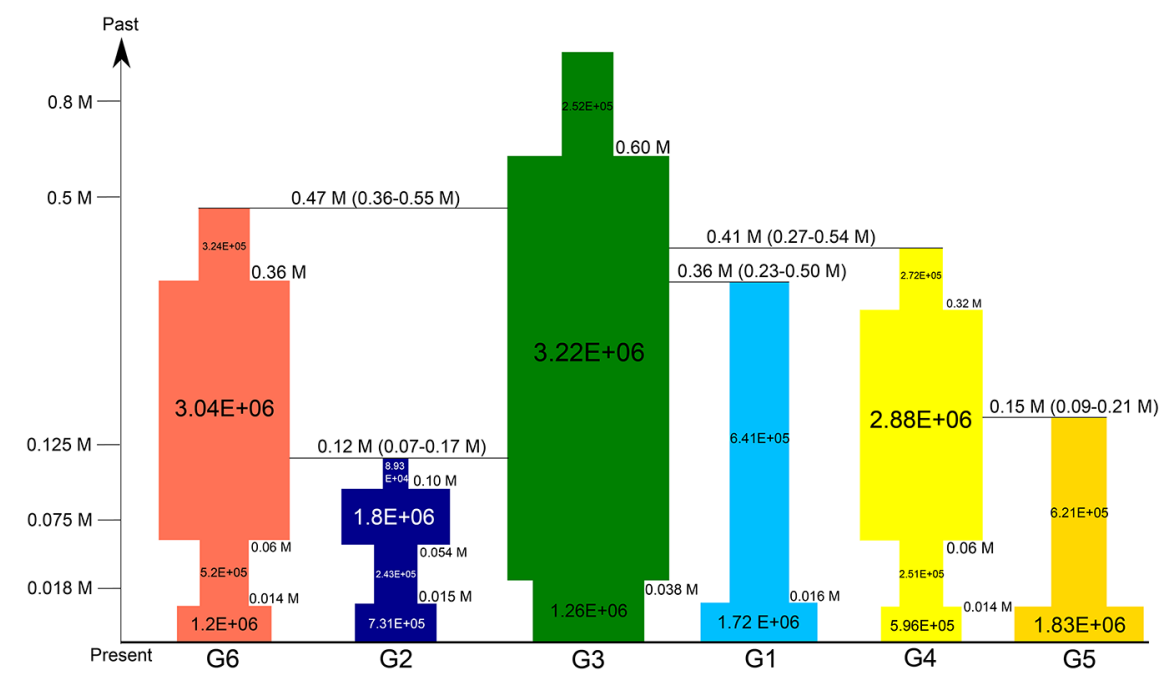

FIGURE 6 | Summary of inferred demographic history of the six groups of $P$. fasciculata. Changes in population sizes are integrated into the divergent scenario. Times on the vertical axis represent the glaciation periods that occurred in the QTP (Zheng et al., 2002). Population sizes are indicated on each square. Times of divergence and changes in population sizes are indicated next to each change in population size. Only the mean values are shown (see Tables $\mathbf{5 8}$ and $\mathbf{5 9}$ for $95 \%$ credible interval for all values). 


\section{Species Distribution Models}

The value AUC obtained for the final consensus model was 0.995, therefore it is an accurate model. The predicted current potential distribution fitted very well with the actual distribution of the species. The predictions to the LGM condition suggested that $P$. fasciculata has retreated to eastern Hengduan Mountains to occupy a large region and some restricted refugia in the eastern Himalayas, while during the MIS19 (a much colder period of Quaternary), the predicted suitable habitat for the species was enormously reduced to a small region in the eastern Hengduan Mountains.

\section{DISCUSSION}

Based on population genomic data, we found a striking population genetic structure for $P$. fasciculata in the highly fragmented biodiversity hotspot of the Hengduan Mountains. The patterns of genetic differentiation detected by different structure analyses were congruent, and we identified six groups of populations that capture the main characteristics of the population history of this species. The results of $A B C$ modeling provided strong support for population divergence driven by Quaternary climatic fluctuations. The comparison of the different demographic scenarios shows that all six groups have experienced bottlenecks or stayed stable during the last glaciation, while five groups started to expand just after the LGM. These results obtained with genomic data were also supported by the SDM analyses. Taking together with a recent study that investigated factors in driving genomic variation in this species (Ren et al., 2018), our results suggest that all the historical factors (i.e., past climatic changes), spatial and environmental variables act as drivers of spatial genetic patterns. This study thus contributes a significant advance to our understanding of how alpine species were genetically structured and responded to Quaternary climatic fluctuations in the Hengduan Mountains and the QTP.

\section{Spatial Patterns of Genomic Diversity}

Our results revealed exceptionally high levels of population divergence across the distribution of $P$. fasciculata, with a mean $F_{\mathrm{ST}}$ value of 0.377 (Table S5). This value is slightly lower than the level of genetic differentiation among populations reported for its closely related species $P$. tibetica (0.450; Ren et al., 2018) and Bulbophyllum occultum (0.387; Jaros et al., 2016), but it is still within the range usually ascribed for plants with particularly restricted dispersal ability. The divergence of populations detected with our neutral genomic markers is thus generally considered "very high" and translates into $<1$ migrant per generation under equilibrium conditions (Conner and Hartl, 2004), a value often considered the minimum for maintaining species cohesion. By contrast, for the species that are characterized by extensive long-distance gene flow facilitated by the dust-like and wind-dispersed pollen and seeds, the level of population differentiation usually exhibits low genetic differentiation among populations (e.g., orchids in general,
$F_{\mathrm{ST}}=0.02-0.116$, Tremblay et al., 2005; epiphytic species, mean $F_{\mathrm{ST}}=0.146$, Phillips et al., 2012; Restio capensis, $F_{\mathrm{ST}}$ $($ RADseq/neutral $)=0.03$, Lexer et al., 2014).

Spatial patterns of nuclear genomic differentiation inferred from STRUCTURE, PCA and BARRIER analyses were largely concordant with each other (Figures 3, 4, and 5B), which suggest a strong correspondence between population differentiation and their geographic locations. The pattern was further supported by the procrustes analysis, which showed a high similarity score between the overall rotated genetic space and their geographic locations (Figure 5A). The persistence of population divergence may be facilitated by the poor dispersal ability of the species (Richards, 2003) and reinforced by the rugged topographic features and profound ecological heterogeneity found in the Hengduan Mountains. Indeed, a recent study has shown that both spatial (i.e., geographic distance and elevation differences between populations) and environmental (i.e., climatic and edaphic variables) factors acted as drivers of population differentiation not only in selected but also in neutral genomic regions (Ren et al., 2018). Such strong correlation may suggest local adaptation, which may have further reinforced the genetic structure (Savolainen et al., 2013; Twyford et al., 2015). Furthermore, historical factors (i.e., past climatic fluctuations) were inferred to drive large-scale spatial genetic structure in this species (see below). Similar spatial, environmental, and historical factors have been suggested to drive spatial genetic patterns in its closely related species $P$. tibetica (Ren et al., 2018) and in a montane pollination-generalist herb (Muñoz-Pajares et al., 2017). By contrast, for P. nutans, another closely related species of $P$. fasciculata, geographic isolation played an important role in driving population divergence (Ren et al., 2018), while for the plant species Restio capensis that occurs in the Cape Floristic Region of South Africa, another biodiversity hotspot in the world, climatic variables were the major drivers of population divergence (Lexer et al., 2014). Therefore, drivers of population differentiation may be different and complex in different taxa and areas, and more factors should be considered when evaluating population differentiation of organisms and in particular for those that are distributed in mountainous areas.

\section{Demographic History of $P$. fasciculata in Response to Quaternary Climatic Fluctuations}

Quaternary climatic fluctuations had a dramatic effect on distribution patterns and phylogeographic structure of species (Comes and Kadereit, 1998; Abbott et al., 2000; Hewitt, 2004), especially for those cold-adapted species distributed in high altitude such as the QTP that are assumed to be particularly vulnerable to past climatic changes (Zheng, 1996; Yao et al., 2007). Despite much effort (reviewed in Liu et al., 2014; Favre et al., 2015), we are lacking a detailed demographic history for the species present in the Hengduan Mountains and QTP because of limited genetic information (e.g., Yang et al., 2008; Du and Wang, 2016; Wan et al., 2016; but see Li et al., 2013; Shang et al., 2015). In this study, our analysis uncovers a detailed Quaternary demographic history of an alpine species distributed 
in the Hengduan Mountains and QTP. It corroborates our previous study on $P$. tibetica, which showed similar effects of the different factors in the Himalayas.

Our test of the different demographic hypotheses done within an $\mathrm{ABC}$ framework shows that populations included in G3 experienced the most ancient expansions ca. 0.60 Ma (HPD: 0.27-0.86 Ma; Figure 6) and all other genetic groups originated from G3. The model comparisons suggest that current populations originated from ancestral populations located in the eastern Hengduan Mountains. The divergence times between the genetic groups and the ancestral populations (Figure 6) are dated after the largest Naynauxungla glaciation that began ca. 1.2 Ma and reached its maximum between 0.8 and 0.5 Ma in the QTP (Shi, 2002; Zheng et al., 2002). This result indicates that the Hengduan Mountains acted as a main refugium for the species to survive during this largest glaciation period, which is also indicated by the SDMs for MIS19 (Figure 7). The Hengduan Mountains as a refugium is also evident in the niche modeling of this species in Ren et al. (2018) and many other studies (e.g., Yang et al., 2008; Li et al., 2013; Du et al., 2017; also reviewed in Muellner-Riehl, 2019). However, a previous study suggested that $P$. fasciculata diverged from its closely related species $P$. tibetica during the Pliocene period $(4.65 \mathrm{Ma})$ and expanded its distributions at the beginning of the Quaternary when the climate became cold (Ren et al., 2018). During the period between 4.65 and 0.6 Ma, it is unlikely that no population divergence had occurred, given the varied topographic features in the region. A more likely explanation would be that extensive extinction of ancestral populations might have occurred during the past environmental changes, most likely during the largest Naynauxungla glaciation, which produced an ice sheet covering an area five to seven times larger than its current range (Shi, 2002; Zheng et al., 2002; Ou et al., 2015). Such extensive ice sheet and extremely cold climate during the largest glaciation could have caused fragmentation of ancestral populations, contributing to isolation and eventual extinction of populations located at high-altitude regions, especially if one considers the fact that all the current northwestern and southwestern populations occur at more than 4,000 m (Table S1). By contrast, the eastern populations, occurring at lower altitude, could have survived in an eastern refugium (Figures 6 and 7) during the largest glaciation. When the climate became less cold, these populations could have recolonized high-altitude areas again and further gave rise to other genetic lineages triggered by the afterward glacial and interglacial events (Wang et al., 2009; Opgenoorth et al., 2010).

The timeframes of the divergence between groups G1, G4, and G6 and the ancestral populations (i.e., G3) are congruent with a period when two other glaciation events and multiple interglacial periods occurred in the QTP and Hengduan Mountains (Ou et al., 2015). The glaciations during this period became progressively less extensive, but a cold climate prevailed in the QTP until 0.17 Ma (Shi, 2002), which may have triggered these divergences. The ABC modeling of changes in populations for each group indicates that both G4 and G6 have experienced ancient expansions while G1 has stayed stable through time until the end of the LGM (Figure 6). Such different demographic changes may depend on their specific ecological niches (e.g., Ren et al., 2017). The current population of G1 occurs at an altitude of $4845 \mathrm{~m}$. The cold climate and fewer available ecological niches as indicated in the SDMs for this population (Figure 7) may have prevented the ancient expansion of this group. By contrast, the current populations of the other two groups G4 and G6 occur at lower altitudes (4,170 $\mathrm{m}$ and average $4,583 \mathrm{~m}$, respectively). The open new habitats may have facilitated their ancient expansions.

Finally, the remaining two groups G2 and G5 were formed in different ways during the last interglacial when the climate was warm (Figure 6). It seems that during the ancient expansions of G6 and ancestral populations (G3), the two groups came into secondary contact and resulted in the formation of G2. The divergence between G5 and G4 may due to complex topographic features in this region (Figure 1). The deep valleys and high mountains may have caused fragmentation of the ancient expansion of G4, reduced gene flow between them and reinforced divergence. Taken together, Quaternary climatic fluctuations pre-dating the LGM have had a much stronger influence on the evolutionary histories of plants in the QTP and Hengduan Mountains than previously thought (Qiu et al., 2011; Li et al., 2013; Muellner-Riehl, 2019), especially the largest glaciation period which may have caused massive extinction of ancient populations of plants (see also Ren et al., 2017). However, the results of this study, combined with previous studies (Wang et al., 2009; Opgenoorth et al., 2010; Ren et al., 2017), clearly indicate that the alpine species in the QTP and its adjacent regions could have survived in different refugia at high altitude, conflicting with Renner's opinion that a unique ice-sheet had covered the QTP (Kuhle, 1998; Renner, 2016). Recently, Muellner-Riehl (2019) has provided a nice glacial map in his Figure 4, which provides the currently most commonly accepted scheme of glaciation in the region. Furthermore, all genetic lineages have experienced bottlenecks or remained stable during the last glaciation and post-glacial expansions. This result, taken together with those recently reported for other alpine herbs (Hu et al., 2016; Wan et al., 2016; Ren et al., 2017), suggests that alpine plant species survived the last glaciation (i.e., 0.015-0.075 Ma) in multiple refugia in the QTP where most of the diverged lineages were preserved.

It should be noted that the timeframes of divergence estimated by DIY-ABC were converted into years using a generation time of one year. Whereas generation times for perennial species could be different and the biological characteristics of the species are not well described, our results using one year per generation are therefore should be treated with caution. However, another study on related species of Primula (Yan et al., 2012) has also used one year to study the demography history of $P$. obconica, and our $\mathrm{ABC}$ results are well consistent with the SDMs under past climatic conditions, which may suggest that a generation time of one year for P. fasciculata is acceptable. Further field and experimental studies are needed to confirm this assumption. 


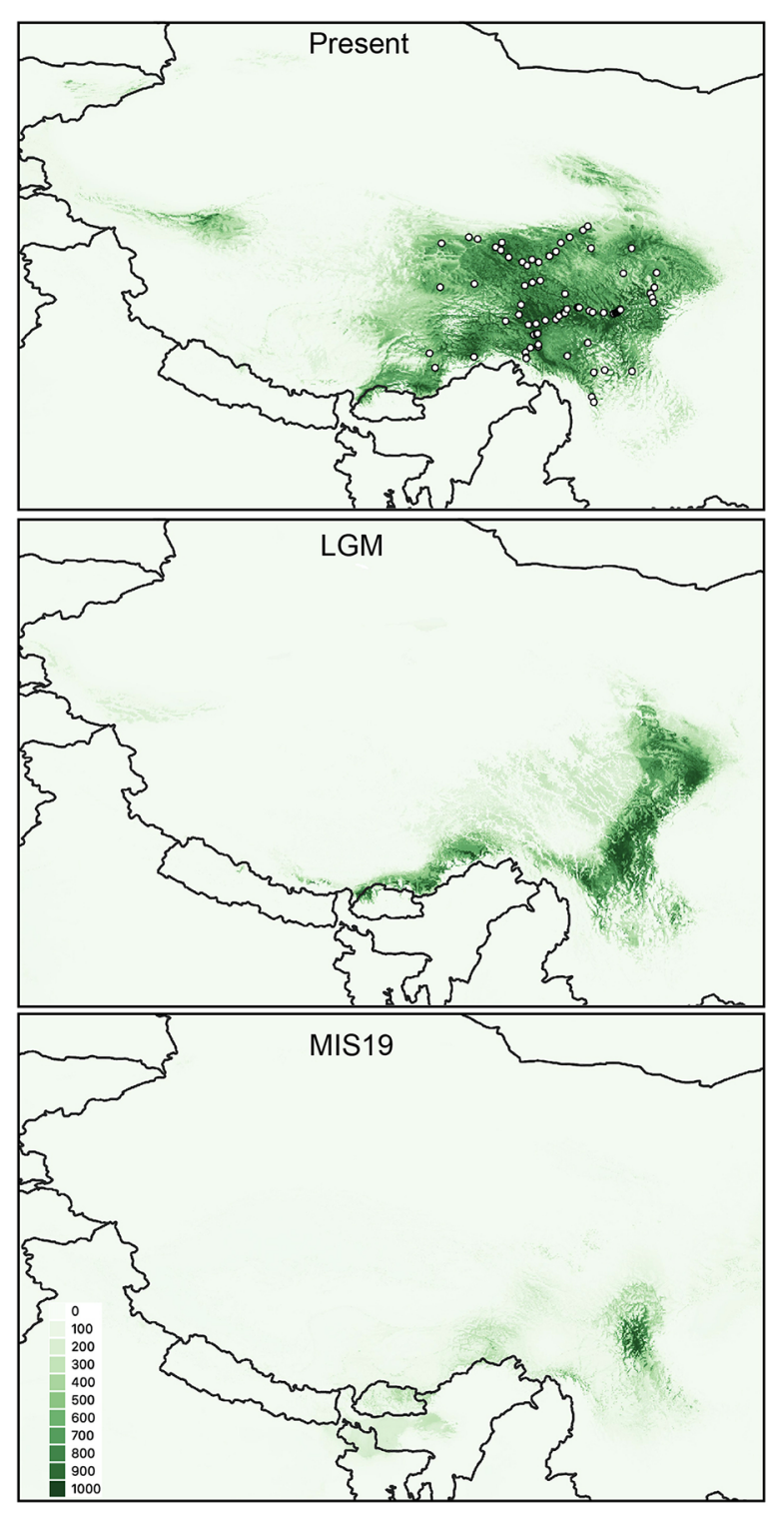

FIGURE 7 | Habitat suitability of $P$. fasciculata predicted by SDMs for the present, the LGM and the MIS19. The white dots represent the 74 presences used to calibrate the models in this study.

\section{CONCLUSIONS}

Our analysis of population genomic data in a spatially and ecologically explicit context using appropriate model comparisons could identify the genetic structure and test several hypotheses about the detailed demographic history of an alpine plant species. Our model-testing framework combined niche modeling allowed us to demonstrate a clear effect of past climatic changes on the intraspecific divergence of $P$. fasciculata. Knowing these possible effects of past climatic changes on current populations may be useful for predicting their future range dynamics in facing ongoing climatic warming and for future management strategies. Although the 12 populations (1720 individuals were selected from each population) are selected from our 54 sampled populations based on geographical distributions and ecological variables, bias on the genetic grouping and inferences regarding populations size and dating may exist because of the relatively small sampling size. More populations, especially the sampling sites with limited dispersal area are needed to further uncover its evolutionary history. Nevertheless, our results on $P$. fasciculata, considered in light of results recently reported for its closely related, Himalayan species P. tibetica (Ren et al., 2017), and a study that investigated interspecific divergence between them (Ren et al., 2018), suggest that the largest glaciation has markedly affected the evolution and demography of these two species. Additionally, it probably caused extensive extinction of their ancestral populations. The ancestors of the current divergence populations may have survived in the Hengduan Mountains refugium or microrefugia in the Himalayas (Xing and Ree, 2017; Muellner-Riehl, 2019). Subsequent episodes of divergence are associated with following climatic fluctuations. By contrast, the LGM had less effect on recently diverged lineages that may have survived in multiple refugia, as also suggested by other studies in this area (e.g., Wang et al., 2009; Opgenoorth et al., 2010; Li et al., 2013; Hu et al., 2016) and in other mountains (e.g., European mountains, Theodoridis et al., 2016; North America, Beatty and Provan, 2010; Anatolian mountains, Ansell et al., 2011; South America, Cosacov et al., 2010; Turchetto-Zolet et al., 2013). This response pattern to past climatic changes may be also applicable for other alpine plant species in the QTP that share a preference for cold environments.

\section{DATA AVAILABILITY STATEMENT}

The dataset of $P$. fasciculata (Dryad doi: https://doi.org/10.5061/ dryad.tt8n46q; File 1-D2) used in Ren et al. (2018) that comprises 234 individuals from 12 populations was reanalyzed in this study.

\section{AUTHOR CONTRIBUTIONS}

GR and NS planned and designed the research. GR carried out the sampling and the laboratory work, performed the molecular analysis. RM performed the SDM analysis. GR and NS wrote the manuscript with the help of EC.

\section{ACKNOWLEDGMENTS}

This work was funded by the National Natural Science Foundation of China (41901056 and 31971391), the Fundamental Research Funds for the Central Universities (lzujbky-2018-99) and the Second Tibetan Plateau Scientific Expedition and Research (STEP) program (2019QZKK0502) to GR, the University of Lausanne research fund, grant 
31003A_138282 from the Swiss National Science Foundation to NS. We received support for computational work from the VitalIT facilities from the Swiss Institute of Bioinformatics. The content of the manuscript has previously appeared in GR's doctoral thesis (Ren, 2017).

\section{REFERENCES}

Abbott, R., Smith, L., Milne, R. I., Crawford, R. M. M., Wolff, K., and Balfour, J. (2000). Molecular Analysis of Plant Migration and Refugia in the Artic. Science 289, 1343-1346. doi: 10.1126/science.289.5483.1343

Ansell, S. W., Stenøien, H. K., Grundmann, M., Russell, S. J., Koch, M. A., Schneider, H., et al. (2011). The importance of Anatolian mountains as the cradle of global diversity in Arabis alpina, a key arctic-alpine species. Ann. Bot. 108, 241-252. doi: 10.1093/aob/mcr134

Antonovics, J. (1968). Evolution in closely adjacent plant populations. V. Evolution of self-fertility. Heredity 23, 219-238. doi: 10.1038/hdy.1968.30

Araújo, M. B., and New, M. (2007). Ensemble forecasting of species distributions. Trends Ecol. Evol. 22, 42-47. doi: 10.1016/j.tree.2006.09.010

Avise, J. C. (2010). Perspective: Conservation genetics enters the genomics era. Conserv. Genet. 11, 665-669. doi: 10.1007/s10592-009-0006-y

Beatty, G. E., and Provan, J. (2010). Refugial persistence and postglacial recolonization of North America by the cold-tolerant herbaceous plant Orthilia secunda. Mol. Ecol. 19, 5009-5021. doi: 10.1111/j.1365294X.2010.04859.x

Bourret, V., Kent, M. P., Primmer, C. R., Vasemägi, A., Karlsson, S., Hindar, K., et al. (2013). SNP-array reveals genome-wide patterns of geographical and potential adaptive divergence across the natural range of Atlantic salmon (Salmo salar). Mol. Ecol. 22, 532-551. doi: 10.1111/mec.12003

Brown, J. L., Hill, D. J., Dolan, A. M., Carnaval, A. C., and Haywood, A. M. (2018). Paleoclim, high spatial resolution paleoclimate surfaces for global land areas. Sci. Data 5, 1-9. doi: 10.1038/sdata.2018.254

Catchen, J., Hohenlohe, P. A., Bassham, S., Amores, A., and Cresko, W. A. (2013). Stacks: An analysis tool set for population genomics. Mol. Ecol. 22, 3124-3140. doi: $10.1111 / \mathrm{mec} .12354$

Comes, H. P., and Kadereit, J. W. (1998). The effect of quaternary climatic changes on plant distribution and evolution. Trends Plant Sci. 3, 432-438. doi: 10.1016/ S1360-1385(98)01327-2

Conner, J. K., and Hartl, D. L. (2004). A Primer of Ecological Genetics (Sunderland, Massachusetts: Sinauer Associates).

Cornuet, J.-M., Ravigné, V., and Estoup, A. (2010). Inference on population history and model checking using DNA sequence and microsatellite data with the software DIYABC (v1.0). BMC Bioinf. 11, 401. doi: 10.1186/1471-2105-11-401

Cornuet, J. M., Pudlo, P., Veyssier, J., Dehne-Garcia, A., Gautier, M., Leblois, R., et al. (2014). DIYABC v2.0: A software to make approximate Bayesian computation inferences about population history using single nucleotide polymorphism, DNA sequence and microsatellite data. Bioinformatics 30, 1187-1189. doi: 10.1093/bioinformatics/btt763

Cosacov, A., Sérsic, A. N., Sosa, V., Johnson, L. A., and Cocucci, A. A. (2010). Multiple periglacial refugia in the Patagonian steppe and post-glacial colonization of the Andes: the phylogeography of Calceolaria polyrhiza. J. Biogeogr. 37, 1463-1477. doi: 10.1111/j.1365-2699.2010.02307.x

Dormann, C. F., Elith, J., Bacher, S., Buchmann, C., Carl, G., Carré, G., et al. (2013). Collinearity: A review of methods to deal with it and a simulation study evaluating their performance. Ecography 36, 27-46. doi: 10.1111/j.16000587.2012.07348.x

Du, Z.-Y., and Wang, Q.-F. (2016). Allopatric divergence of Stuckenia filiformis (Potamogetonaceae) on the Qinghai-Tibet Plateau and its comparative phylogeography with S. pectinata in China. Sci. Rep. 6, 20883. doi: 10.1038/ srep20883

Du, F. K., Hou, M., Wang, W., Mao, K., and Hampe, A. (2017). Phylogeography of Quercus aquifolioides provides novel insights into the Neogene history of a major global hotspot of plant diversity in south-west China. J. Biogeogr. 44, 294-307. doi: 10.1111/jbi.12836

Earl, D. A., and VonHoldt, B. M. (2012). STRUCTURE HARVESTER: A website and program for visualizing STRUCTURE output and implementing the

\section{SUPPLEMENTARY MATERIAL}

The Supplementary Material for this article can be found online at: https://www.frontiersin.org/articles/10.3389/fpls.2020.00986/ full\#supplementary-material

Evanno method. Conserv. Genet. Resour. 4, 359-361. doi: 10.1007/s12686 011-9548-7

Emerson, K. J., Merz, C. R., Catchen, J. M., Hohenlohe, P., Cresko, W., Bradshaw, W. E., et al. (2010). Resolving postglacial phylogeography using highthroughput sequencing. Proc. Natl. Acad. Sci. U. S. A. 107, 16196-16200. doi: $10.1073 /$ pnas.1006538107

Evanno, G., Regnaut, S., and Goudet, J. (2005). Detecting the number of clusters of individuals using the software STRUCTURE: A simulation study. Mol. Ecol. 14, 2611-2620. doi: 10.1111/j.1365-294X.2005.02553.x

Favre, A., Päckert, M., Pauls, S. U., Jähnig, S. C., Uhl, D., Michalak, I., et al. (2015). The role of the uplift of the Qinghai-Tibetan Plateau for the evolution of Tibetan biotas. Biol. Rev. 90, 236-253. doi: 10.1111/brv.12107

Fordham, D. A., Saltré, F., Haythorne, S., Wigley, T. M. L., Otto-Bliesner, B. L., Chan, K. C., et al. (2017). PaleoView: a tool for generating continuous climate projections spanning the last 21000 years at regional and global scales. Ecography 40, 1348-1358. doi: 10.1111/ecog.03031

Guisan, A., and Zimmermann, N. E. (2000). Predictive habitat distribution models in ecology. Ecol. Modell 135, 147-186. doi: 10.1016/S0304-3800(00)00354-9

Hewitt, G. M. (2004). Genetic consequences of climatic oscillations in the Quaternary. Philos. Trans. R. Soc Lond. B. Biol. Sci. 359, 183-195. doi: 10.1098/rstb.2003.1388

$\mathrm{Hu}, \mathrm{C}$. , and Kelso, S. (1996). "Primulaceae," in Flora of China (Beijing: Science Press), 99-185.

Hu, Q., Peng, H., Bi, H., Lu, Z., Wan, D., Wang, Q., et al. (2016). Genetic homogenization of the nuclear ITS loci across two morphologically distinct gentians in their overlapping distributions in the Qinghai-Tibet Plateau. Sci. Rep. 6, 34244. doi: 10.1038/srep34244

Jakobsson, M., and Rosenberg, N. A. (2007). CLUMPP: A cluster matching and permutation program for dealing with label switching and multimodality in analysis of population structure. Bioinformatics 23, 1801-1806. doi: 10.1093/ bioinformatics/btm233

Jaros, U., Fischer, G. A., Pailler, T., and Comes, H. P. (2016). Spatial patterns of AFLP diversity in Bulbophyllum occultum (Orchidaceae) indicate long-term refugial isolation in Madagascar and long-distance colonization effects in La Réunion. Heredity 116, 434-446. doi: 10.1038/hdy.2016.1

Jombart, T. (2008). Adegenet: A R package for the multivariate analysis of genetic markers. Bioinformatics 24, 1403-1405. doi: 10.1093/bioinformatics/btn129

Karger, D. N., Conrad, O., Böhner, J., Kawohl, T., Kreft, H., Soria-Auza, R. W., et al. (2017). Climatologies at high resolution for the earth's land surface areas. Sci. Data 4, 1-20. doi: 10.1038/sdata.2017.122

Kuhle, M. (1998). Reconstruction of the 2.4 million $\mathrm{km}^{2}$ late Pleistocene ice sheet on the Tibetan Plateau and its impact on the global climate. Quat. Int. 45, 71108. doi: 10.1016/j.tree.2014.10.004

Lanier, H. C., Massatti, R., He, Q., Olson, L. E., and Lacey Knowles, L. (2015). Colonization from divergent ancestors: Glaciation signatures on contemporary patterns of genomic variation in Collared Pikas (Ochotona collaris). Mol. Ecol. 24, 3688-3705. doi: $10.1111 / \mathrm{mec} .13270$

Lexer, C., Wüest, R. O., Mangili, S., Heuertz, M., Stölting, K. N., Pearman, P. B., et al. (2014). Genomics of the divergence continuum in an African plant biodiversity hotspot, I: Drivers of population divergence in Restio capensis (Restionaceae). Mol. Ecol. 23, 4373-4386. doi: 10.1111/mec.12870

Li, J., and Fang, X. (1999). Uplift of the Tibetan Plateau and environmental changes. Chin. Sci. Bull. 44, 2117-2124. doi: 10.1007/BF03182692

Li, L., Abbott, R. J., Liu, B., Sun, Y., Li, L., Zou, J., et al. (2013). Pliocene intraspecific divergence and Plio-Pleistocene range expansions within Picea likiangensis (Lijiang spruce), a dominant forest tree of the Qinghai-Tibet Plateau. Mol. Ecol. 22, 5237-5255. doi: 10.1111/mec.12466

Liu, J. Q., Gao, T. G., Chen, Z. D., and Lu, A. M. (2002). Molecular phylogeny and biogeography of the Qinghai-Tibet Plateau endemic Nannoglottis (Asteraceae). Mol. Phylogenet. Evol. 23, 307-325. doi: 10.1016/S1055-7903(02)00039-8 
Liu, J. Q., Wang, Y. J., Wang, A. L., Hideaki, O., and Abbott, R. J. (2006). Radiation and diversification within the Ligularia-Cremanthodium-Parasenecio complex (Asteraceae) triggered by uplift of the Qinghai-Tibetan Plateau. Mol. Phylogenet. Evol. 38, 31-49. doi: 10.1016/j.ympev.2005.09.010

Liu, J., Möller, M., Provan, J., Gao, L. M., Poudel, R. C., and Li, D. Z. (2013). Geological and ecological factors drive cryptic speciation of yews in a biodiversity hotspot. New Phytol. 199, 1093-1108. doi: 10.1111/nph.12336

Liu, J. Q., Duan, Y. W., Hao, G., Ge, X. J., and Sun, H. (2014). Evolutionary history and underlying adaptation of alpine plants on the Qinghai-Tibet Plateau. J. Syst. Evol. 52, 241-249. doi: 10.1111/jse.12094

Loveless, M. D., and Hamrick, J. L. (1984). Ecological Determinants of Genetic Structure in Plant Populations. Annu. Rev. Ecol. Syst. 15, 65-95. doi: 10.1146/ annurev.es.15.110184.000433

Manni, F., Guerard, E., and Heyer, E. (2004). Geographic patterns of (genetic, morphologic, linguistic) variation: How barriers can be detected by using Monmonier's algorithm. Hum. Biol. 76, 173-190. doi: 10.1353/hub.2004.0034

Meirmans, P. G., and Van Tienderen, P. H. (2004). GENOTYPE and GENODIVE: Two programs for the analysis of genetic diversity of asexual organisms. Mol. Ecol. Notes 4, 792-794. doi: 10.1111/j.1471-8286.2004.00770.x

Mosbrugger, V., Favre, A., Muellner-Riehl, A. N., Päckert, M., and Mulch, A. (2018). "Cenozoic Evolution of Geo-Biodiversity in the Tibeto-Himalayan Region," in Mountains, Climate, and Biodiversity. Eds. C. Hoorn, A. Perrigio and A. Antonelli (Chichester: Wiley-Blackwell), 429-448.

Muñoz-Pajares, A. J., García, C., Abdelaziz, M., Bosch, J., Perfectti, F., and Gómez, J. M. (2017). Drivers of genetic differentiation in a generalist insect-pollinated herb across spatial scales. Mol. Ecol. 26, 1576-1585. doi: 10.1111/mec.13971

Muellner-Riehl, A. N. (2019). Mountains as evolutionary arenas: Patterns, emerging approaches, paradigm shifts, and their implications for plant phylogeographic research in the tibeto-himalayan region. Front. Plant Sci. 10, 195. doi: $10.3389 /$ fpls.2019.00195

Mulch, A., and Chamberlain, C. P. (2006). Earth science: The rise and growth of Tibet. Nature 439, 670-671. doi: 10.1038/439670a

Myers, N., Mittermeier, R. A., Mittermeier, C. G., da Fonseca, G. A. B., and Kent, J. (2000). Biodiversity hotspots for conservation priorities. Nature 403, 853-858. doi: $10.1038 / 35002501$

Narum, S. R., Buerkle, C. A., Davey, J. W., Miller, M. R., and Hohenlohe, P. A. (2013). Genotyping-by-sequencing in ecological and conservation genomics. Mol. Ecol. 22, 2841-2847. doi: 10.1111/mec.12350

Oksanen, J., Blanchet, F. G., Kindt, R., Legendre, P., Minchin, P. R., Simpson, G. L., et al. (2013). vegan: Community Ecology Package, CRAN R package v.2.0-7. URL http://CRAN.R-project.org/package=vegan.

Opgenoorth, L., Vendramin, G. G., Mao, K., Miehe, G., Miehe, S., Liepelt, S., et al. (2010). Tree endurance on the Tibetan Plateau marks the world's highest known tree line of the Last Glacial Maximum. New Phytol. 185, 332-342. doi: 10.1111/j.1469-8137.2009.03007.x

Ou, X., Zhou, S., Lai, Z., and Zeng, L. (2015). Discussions on quaternary glaciations and their climatic responding in the Qinghai-Tibetan Plateau. Quat. Sci. 35 (1), 12-28. (in Chinese). doi: 10.11928/j.issn.1001-7410.2015.01.02

Phillips, R. D., Dixon, K. W., and Peakall, R. (2012). Low population genetic differentiation in the Orchidaceae: Implications for the diversification of the family. Mol. Ecol. 21, 5208-5220. doi: 10.1111/mec.12036

Pritchard, J. K., Stephens, M., and Donelly, P. (2000). Inference of population structure using multilocus genotype data. Genetics 155, 945-959.

Qiu, Y.-X., Fu, C.-X., and Comes, H. P. (2011). Plant molecular phylogeography in China and adjacent regions: Tracing the genetic imprints of Quaternary climate and environmental change in the world's most diverse temperate flora. Mol. Phylogenet. Evol. 59, 225-244. doi: 10.1016/j.ympev.2011.01.012

Ren, G., Conti, E., and Salamin, N. (2015). Phylogeny and biogeography of Primula sect. Armerina: implications for plant evolution under climate change and the uplift of the Qinghai-Tibet Plateau. BMC Evol. Biol. 15, 161. doi: 10.1186/s12862-015-0445-7

Ren, G., Mateo, G., Liu, J., Suchan, T., Alvarez, N., Guisan, A., et al. (2017). Genetic consequences of Quaternary climatic oscillations in the Himalayas: Primula tibetica as a case study based on restriction site-associated DNA sequencing. New Phytol. 213, 1500-1512. doi: 10.1111/NPH.14221

Ren, G., Mateo, R. G., Guisan, A., Conti, E., and Salamin, N. (2018). Species divergence and maintenance of species cohesion of three closely related Primula species in the Qinghai-Tibet Plateau. J. Biogeogr. 45, 2495-2507. doi: 10.1111/jbi.13415
Ren, G. (2017). Genetic consequences of historically geological and climatic events in Qinghai-Tibet Plateau: the Primula section Armerina as a case study [doctor"s thesis] (Switzerland: University of Lausanne).

Renner, S. S. (2016). Available data point to a $4-\mathrm{km}$-high Tibetan Plateau by 40 $\mathrm{Ma}$, but 100 molecular-clock papers have linked supposed recent uplift to young node ages. J. Biogeogr. 43, 1479-1487. doi: 10.1111/jbi.12755

Richards, J. (2003). Primula. 2nd ed. (Portland, OR: Timber Press, USA).

Rosenberg, N. A. (2004). DISTRUCT: A program for the graphical display of population structure. Mol. Ecol. Notes 4, 137-138. doi: 10.1046/j.1471-8286.2003.00566.x

Savolainen, O., Lascoux, M., and Merilä, J. (2013). Ecological genomics of local adaptation. Nat. Rev. Genet. 14, 807-820. doi: 10.1038/nrg3522

Shafer, A. B. A., and Wolf, J. B. W. (2013). Widespread evidence for incipient ecological speciation: a meta-analysis of isolation-by-ecology. Ecol. Lett. 16, 940-950. doi: 10.1111/ele.12120

Shang, H.-Y., Li, Z.-H., Dong, M., Adams, R. P., Miehe, G., Opgenoorth, L., et al. (2015). Evolutionary origin and demographic history of an ancient conifer (Juniperus microsperma) in the Qinghai-Tibetan Plateau. Sci. Rep. 5, 10216. doi: 10.1038/srep10216

Shi, Y. (2002). Characteristics of late Quaternary monsoonal glaciation on the Tibetan Plateau and in East Asia. Quat. Int. 97, 79-91. doi: 10.1016/S10406182(02)00053-8

Theodoridis, S., Randin, C., Szövényi, P., Boucher, F. C., Patsiou, T. S., and Conti, E. (2016). How Do Cold-Adapted Plants Respond to Climatic Cycles? Interglacial Expansion Explains Current Distribution and Genomic Diversity in Primula farinosa L. Syst. Biol. 66, 715-736. doi: 10.1093/sysbio/syw114

Thuiller, W., Lafourcade, B., Engler, R., and Araújo, M. B. (2009). BIOMOD - a platform for ensemble forecasting of species distributions. Ecography 32, 369373. doi: $10.1111 / \mathrm{j} .1600-0587.2008 .05742 . \mathrm{x}$

Tremblay, R. L., Ackerman, J. D., Zimmerman, J. K., and Calvo, R. N. (2005), Variation in sexual reproduction in orchids and its evolutionary consequences: A spasmodic journey to diversification. Biol. J. Linn. Soc 84, 1-54. doi: 10.1111/ j.1095-8312.2004.00400.x

Turchetto-Zolet, A. C., Pinheiro, F., Salgueiro, F., and Palma-Silva, C. (2013). Phylogeographical patterns shed light on evolutionary process in South America. Mol. Ecol. 22, 1193-1213. doi: 10.1111/mec.12164

Twyford, A. D., Kidner, C. A., and Ennos, R. A. (2015). Maintenance of species boundaries in a Neotropical radiation of Begonia. Mol. Ecol. 24, 4982-4993. doi: $10.1111 /$ mec. 13355

Wan, D. S., Feng, J. J., Jiang, D. C., Mao, K. S., Duan, Y. W., Miehe, G., et al. (2016). The Quaternary evolutionary history, potential distribution dynamics, and conservation implications for a Qinghai-Tibet Plateau endemic herbaceous perennial, Anisodus tanguticus (Solanaceae). Ecol. Evol. 6, 1977-1995. doi: 10.1002/ece3.2019

Wang, L. Y., Ikeda, H., Liu, T. L., Wang, Y. J., and Liu, J. Q. (2009). Repeated range expansion and glacial endurance of Potentilla glabra (Rosaceae) in the Qinghai-Tibetan Plateau. J. Integr. Plant Biol. 51, 698-706. doi: 10.1111/ j.1744-7909.2009.00818.x

Wang, C., Szpiech, Z., Degnan, J., Jakobsson, M., Pemberton, T., Hardy, J., et al. (2010). Comparing spatial maps of human population-genetic variation using procrustes analysis. Stat. Appl. Genet. Mol. Biol. 9, 13. doi: 10.2202/1544-6115.1493

Wang, C., Zöllner, S., and Rosenberg, N. A. (2012). A Quantitative Comparison of the Similarity between Genes and Geography in Worldwide Human Populations. PloS Genet. 8, e1002886. doi: 10.1371/journal.pgen.1002886

Wang, I. J., Glor, R. E., and Losos, J. B. (2013). Quantifying the roles of ecology and geography in spatial genetic divergence. Ecol. Lett. 16, 175-182. doi: 10.1111/ ele. 12025

Wen, J., Zhang, J. Q., Nie, Z. L., Zhong, Y., and Sun, H. (2014). Evolutionary diversifications of plants on the Qinghai-Tibetan Plateau. Front. Genet. 5, 1-16. doi: 10.3389 /fgene.2014.00004

Wright, S. (1943). Isolation by Distance. Genetics 28, 114-138. doi: 10.1186/14712156-6-13

Wu, C. (1987). Flora of Tibet (Beijing: Science Press).

Xing, Y., and Ree, R. H. (2017). Uplift-driven diversification in the Hengduan Mountains, a temperate biodiversity hotspot. Proc. Natl. Acad. Sci. U. S. A. 114, 3444-3451. doi: 10.1073/pnas.1616063114

Yan, H. F., Zhang, C. Y., Wang, F. Y., Hu, C. M., Ge, X. J., and Hao, G. (2012). Population Expanding with the Phalanx Model and Lineages Split by Environmental Heterogeneity: A Case Study of Primula obconica in Subtropical China. PloS One 7, e41315. doi: 10.1371/journal.pone.0041315 
Yang, F. S., Li, Y. F., Ding, X., and Wang, X. Q. (2008). Extensive population expansion of Pedicularis longiflora (Orobanchaceae) on the Qinghai-Tibetan Plateau and its correlation with the Quaternary climate change. Mol. Ecol. 17, 5135-5145. doi: 10.1111/j.1365-294X.2008.03976.x

Yao, T., Pu, J., Lu, A., Wang, Y., and Yu, W. (2007). Recent Glacial Retreat and Its Impact on Hydrological Processes on the Tibetan Plateau, China, and Surrounding Regions. Arctic Antarct. Alp. Res. 39, 642-650. doi: 10.1657/ 1523-0430(07-510)[YAO]2.0.CO;2

Zheng, H., Powell, C. M., An, Z., Zhou, J., and Dong, G. (2000). Pliocene uplift of the northern Tibetan Plateau. Geology 28, 715. doi: 10.1130/0091-7613(2000) 28<715:PUOTNT>2.0.CO;2

Zheng, B., Xu, Q., and Shen, Y. (2002). The relationship between climate change and Quaternary glacial cycles on the Qinghai-Tibetan Plateau: review and speculation. Quat. Int. 97, 93-101. doi: 10.1016/S1040-6182(02)00054-X
Zheng, D. (1996). The system of physico-geographical regions of the QinghaiXizang (Tibet) plateau. Sci. China Ser. D. 39, 410-417.

Conflict of Interest: The authors declare that the research was conducted in the absence of any commercial or financial relationships that could be construed as a potential conflict of interest.

Copyright (c) 2020 Ren, Mateo, Conti and Salamin. This is an open-access article distributed under the terms of the Creative Commons Attribution License (CC BY). The use, distribution or reproduction in other forums is permitted, provided the original author(s) and the copyright owner(s) are credited and that the original publication in this journal is cited, in accordance with accepted academic practice. No use, distribution or reproduction is permitted which does not comply with these terms. 